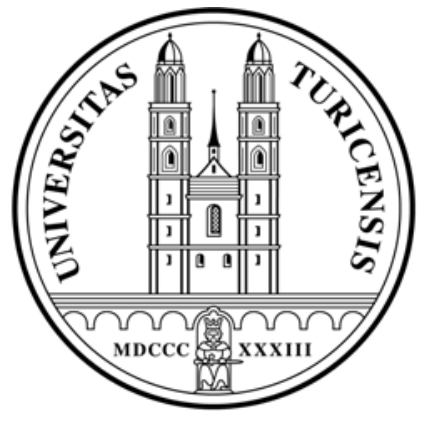

Institute for Empirical Research in Economics

University of Zurich

Working Paper Series

ISSN 1424-0459

Working Paper No. 468

Habit formation, strategic extremism, and debt policy

Egil Matsen and Øystein Thøgersen

January 2010 


\title{
Habit formation, strategic extremism, and debt policy
}

\author{
Egil Matsen \\ Dept. of Economics, Norwegian University of Science and Technology, NTNU, NO-7491 Trondheim, \\ Norway. Email: egil.matsen@svt.ntnu.no Phone: +47 73597852 \\ Øystein Thøgersen \\ Dept. of Economics, Norwegian School of Economics and Business Administration, and CESifo, \\ Helleveien 30, NO-5045 Bergen, Norway. Email: oystein.thogersen@nhh.no
}

\begin{abstract}
We suggest a probabilistic voting model where voters' preferences for alternative public goods display habit formation. Current policies determine habit levels and in turn the future preferences of the voters. This allows the incumbent to act strategically in order to influence the probability of reelection.

Comparing to a benchmark case of a certain reelection, we demonstrate that the incumbent's optimal policy features both a more polarized allocation between the alternative public goods and a debt bias.
\end{abstract}

JEL classification: D72, D78, H62

Keywords: Budget deficits; voting; extremism; habit formation

\footnotetext{
* We are indebted to Rune Jansen Hagen, Erling Holmøy, William F. Shughart, Ragnar Torvik, Fabrizio Zilibotti, and two anonymous referees for valuable suggestions and comments. We also appreciate helpful comments from seminar participants in Bergen, Garmisch, Maastricht, Stavanger and Zurich. Part of this research was done while Matsen was a visiting Professor at the Chair of Political Economy and Macroeconomics of the IEW-University of Zurich. We thank the IEW for the hospitality and the inputs we got from many of its researchers.
} 


\section{Introduction}

A hundred days into George W. Bush's presidency, The Economist entitled its cover story “That shocking conservative”. The story was about the common perception among political commentators and pundits of a president pushing a much more conservative agenda, on e.g., tax cuts, than his campaign platform had suggested. Glaeser et al. (2005) provide more systematic evidence showing that politicians often implement policies that are more extreme than their political platforms. They report that Democrats and Republicans in the United States on the one hand have very similar, moderate platforms on tax policy. On the other hand evidence reveals rather big differences in mean tax rates between Democratic and Republican administrations.

An account by McCarty et al. (2006) argues convincingly that increased polarization in US policy is observed along several dimensions, including taxes, minimum wages, immigration and social assistance. Moreover, polarization is also evident in the debate related to issues like abortion and religious values in general (Glaeser et al. 2005). Thus, "speaking of convergence in American politics today seems completely out of touch with reality" according to a recent paper by Alesina and Holden (2008: 2). Alesina and Holden also point at experience from the French presidential election in 2007 as well as the 2008 legislative elections in Italy and Spain as evidence of polarization.

Polarization and extreme outcomes may also characterize decisions related to public spending and its composition. A prominent example is the sharp increase in defense spending during the Reagan administrations in the United States. In his campaign, Reagan had run on a strong defense platform. Then, his first budget increased spending by much more than expected by the top military staff. In his memoirs, retired general and Joint Chiefs of Staff, Colin Powell (1995: 258-259) describes this in highly illustrative and amusing terms: "This was Christmas in January. This was tennis without a net." According to Powell, the military leaders got even more money than they asked for according to their submitted “dream lists” of projects. It turned out that the first defense budget of the Reagan administration managed to increase the inherited budget of the preceding Carter administration by $11 \%$.

Why would an elected politician want to pursue more extreme policies than his party platform suggests? One possibility is that party leaders have extreme preferences (Alesina 1988) which in turn can lead to implementation of more extreme policies than indicated by the electoral platforms (Glaeser et al. 2005). While politicians' ideological preferences are important, we would still expect the desire for reelection to moderate policies that seem extreme relative to voters’ preferences.

This paper demonstrates that extreme policies in terms of a more polarized resource allocation may occur not because the incumbent has extreme preferences, but because it makes the incumbent's desired future policy appeal to a larger group of voters. More specifically, we suggest that voters' preferences are characterized by reference levels that are affected by current policies, and politicians can use this link strategically to influence the probability of reelection. 
We consider a political framework where potential partisan governments disagree with respect to the composition of public spending, as in Alesina and Tabellini (1990) (henceforth "AT”) and Tabellini and Alesina (1990) (henceforth “TA”). Crucially, we suggest that voters' utilities over given levels of spending on each public good depends on how that level compares to what they are used to, i.e., their habit level. Compared to a benchmark case of a certain reelection, this gives the incumbent incentives to implement more polarized allocations. By supplying more today of his most preferred public good, the incumbent can push up voters' habit levels and correspondingly their future marginal utility of this good. This will increase the probability of reelection.

The assumption that preferences are characterized by reference dependence in the form of habit formation has been explored in many branches of economics recently (but, to our knowledge, this paper represents the first attempt in the field of political economy.) It is most common in studies of consumption; see Deaton (1992) for a survey. ${ }^{1}$ More recently, it has proved to be successful in stochastic, consumption-based analyses of asset prices; see, for example, Campbell and Cochrane (1999), and also in studies of growth (Carroll et al. 2000) and stabilization policy (Ljungqvist and Uhlig 2000). Habit formation implies that the satisfaction an individual realizes from a given consumption level tends to depend more on the change in consumption (i.e., the deviation between actual consumption and a historically determined habit level) than on the level itself.

The habit formation hypothesis is in accordance with psychological research that suggests that individuals' satisfaction is determined by actual outcome relative to some reference level; see, for example, Fredrick and Loewenstein (1999), Rabin (1998, 2002), Caporale et al. (2007), and also the prominent prospect theory of Kahneman and Tversky (1979).

Traditionally, the assumption of habit formation has been related to individuals' private consumption. We will argue, however, that habit formation is equally important for any voter's preferences for most types of public goods. This is consistent with the findings of Solnick and Hemenway (2005) who report preliminary evidence in favor of reference dependence in the evaluation of public goods. ${ }^{2}$ For example, habit formation seems crucial for voters’ welfare assessments of the spending levels on essential public goods like schools and education, health services, and maintenance of roads and other types of infrastructure. ${ }^{3}$ Consistent with our specification of habit formation below, we assume that increased spending on one of these types of goods today will raise the associated habit level of the voters and increase their marginal utility of a given future spending level.

\footnotetext{
${ }^{1}$ The general idea of habit formation in consumption seems to be formulated by James Duesenberry; see, for example, Duesenberry (1949). Other early contributions include Ryder and Heal (1973) and Easterlin (1974).

${ }^{2}$ Solnick and Hemenway (2005) analyze positional concerns as determinants of reference levels, analogous to external habit formation in some other contributions to this literature.

${ }^{3}$ What we have in mind is mainly the public consumption part of such spending - and not the real investment part. This includes wage expenditures, maintenance, repair and various operating expenditures. The argument is_that the habit formation mechanism is not necessarily related to the investments in, say, hospital or school buildings, but to the quality and volume of public services provided from these buildings. Going back to the jump in defense spending during the Reagan years, which was highlighted above, we note that Powell (1995) stresses that the generous budget to a large extent funded what he called "bread and butter expenditures" just like wages, training, maintenance and spare parts (i.e. public consumption items).
} 
It is also likely that habit formation is relevant for voters' assessment of particular transfer schemes or the social security system in general. This is in accordance with Romer's (1996) analysis of the political process leading to the implementation of the US social security program back in the 1930s. President Roosevelt at that stage created an entitlement for a large number of people to future social security benefits. According to Romer, this changed the political dynamics. If a successor tried to scale back the program, that would "induce anger and a taste for retribution in large numbers of voters” (p. 199). This line of reasoning seems fully consistent with our idea that voters' preferences change in favor of the incumbent's spending priorities due to habit formation.

Models of political behavior generally assume that voters' policy preferences are exogenous to actual policies. ${ }^{4}$ There is, however, a scant literature that captures feedback effects from policies to preferences. For example, Cassing and Hillman (1986) model the interaction between the size of an industry and the political support it receives in terms of protection, for example, by means of tariff policy. The current level of protection influences the size of the industry. In the next stage, this feeds back on political preferences because changes in industry size alter the political gains and costs of a given level of protection.

Cukierman and Tommasi (1998) explain how the implementation of significant policy reversals hinges on the ability of the incumbent to signal successfully the importance of this particular policy move. Given that voters are imperfectly informed about how varying external circumstances influence the mapping from policies to outcome, today's announcement of policy platform provides a signal that in the next stage feeds back on voters' assessment of the policy and consequently on their voting behavior that ultimately determines whether the platform is implemented.

The German reunification of 1990 seems to provide evidence for the existence of important feedback effects from economic policy to individual preferences. Alesina and Fuchs-Schündeln (2007) use the reunification as a "natural experiment" to test the relationship between political regime and individual preferences. They strongly conclude that there is a causal link from policies to preferences. Alesina and Fuchs-Schündeln identify the fact that people "get used to" certain policies as one of the reasons for this link. Our model takes this fact seriously in the sense that we model how current policies determine habits and the future preferences of the voters.

We are not the first to analyze how political extremism can appear for strategic (i.e., votemaximizing) reasons. Glaeser et al. (2005) present a model where strategic extremism occurs because it energizes the incumbent's core constituents more than it energizes the opponent's supporters. ${ }^{5}$ Note, however, that they focus on extreme platforms rather than actual policies. Indeed, their model predicts

\footnotetext{
${ }^{4}$ An exception is retrospective voting models where voters punish the incumbent by voting against him if he acted against their interests when in office. In contrast to this backward-looking model, voters are fully forward-looking in our set-up. We also note that models of directional voting (see Rabinowitz and Macdonald 1989) give the status quo a central role in voting behavior. As in our analysis, this model incorporates a reference point in decision making. Unlike in our model, however, the reference point gives voters incentives to vote strategically; our reference points give politicians incentives to act strategically.

${ }^{5}$ Closely related is the idea that extremism reflects candidates' attempts to obtain campaign contributions; see Alesina and Holden (2008).
} 
that extremism in policies is due to extreme preferences of candidates, whereas platform extremism occurs for strategic reasons. Our analysis shows that extreme actual policies also can occur for strategic reasons. We share this feature with Glazer et al. (1998). They explore a model where an incumbent has incentives to implement extreme policies because it creates a cost to voters of changing the party in power. Their results hinge critically on the assumptions that there is a fixed cost associated with a policy change and that politicians are (partly) office motivated. This contrasts with our model where parties are outcome oriented and the election winner can implement preferred policies without any frictions.

Our paper is closely related to the strategic debt literature initiated by Aghion and Bolton (1990), Persson and Svensson (1989), AT (1990) and TA (1990). ${ }^{6}$ Building on the models of AT and (particularly) TA, we explore a model where different potential governments disagree about the composition of public goods provision. ${ }^{7}$ As extensions, we include probabilistic voting and habit formation in voters' preferences for public goods. It turns out that the extreme resource allocation of the incumbent is accompanied by a strategic debt bias. This debt bias is caused exclusively by the incumbent's attempt to influence the probability of reelection. As explained in more detail below, it complements the strategic debt effects identified by AT and TA.

The next section of this paper presents our model, and briefly discusses the benchmark case where the initial government is certain about reelection. Section 3 considers equilibrium policies when the incumbent acts strategically in the face of uncertainty about reelection. Section 4 offers some final remarks.

\section{An intertemporal model with probabilistic voting}

Adopting the probabilistic voting approach of Persson and Tabellini (2000, section 13.3), we consider a political environment consisting of two competing political parties $(J=D, R)$ with two associated natural constituencies in the form of identically large groups of voters $(j=d, r)$. The two parties are outcome oriented and, following AT (1990) and TA (1990); they disagree about the composition of public spending. As did TA, we consider a two-period framework. For simplicity, we disregard discounting of utility and assume that the real interest rate is zero.

\footnotetext{
${ }^{6}$ This strategic debt literature is part of the broader literature on how an incumbent can influence potential successors by altering alternative state variables. For example, Cukierman et al. (1992) apply this idea to taxation, while Glazer (1989) considers the choice of public investments in this context. Crain (2001) survey's the early literature on strategic fiscal policy, and discusses how it is related to models of the durability of political institutions.

${ }^{7}$ The alternative approach taken by Persson and Svensson (1989) is to assume that governments disagree about the public spending level vs. private consumption.
} 


\subsection{Parties}

Party $J$ is characterized by the period-utility function

(1) $\quad u_{t}^{J}=\alpha^{J} \log f_{t}+\left(1-\alpha^{J}\right) \log g_{t}$,

where $f_{t}$ and $g_{t}$ are the spending levels on the two public goods in period $t, t=1,2$. The parameter $\alpha^{J}, 0 \leq \alpha^{J} \leq 1$, captures the preferences of party $J$ for the composition of the goods. Party $R$ attaches a higher weight to the utility of $f_{t}$ than party $D$, i.e., $\alpha^{R}>\alpha^{D}$ and we assume, as Persson and Tabellini, that $\alpha^{R}=1-\alpha^{D}>\frac{1}{2}$. For concreteness, we assume that the period 1 incumbent is an $R$ government. Because the model is symmetric in every aspect, all results generalize directly to the case of an incumbent $D$-government. As we will highlight and explain below, our specification of log utility has the intended, appealing property that it allows us to focus exclusively on the strategic effects of current policies on the reelection probability of the incumbent.

The government in each period is endowed with one unit of output and has access to a perfect global financial market. Thus, the resource constraints are given by

$$
f_{1}+g_{1}=1+b
$$

and

$$
f_{2}+g_{2}=1-b,
$$

where $b$ is public debt.

As discussed in the introduction, $f_{t}$ and/or $g_{t}$, could be interpreted quite broadly, and might capture the magnitude of the social security program or particular transfer schemes. Stretching the model, we might even imagine that the two goods capture the magnitude of resources available for respectively private and public spending. ${ }^{8}$

In period 1 the incumbent $R$-government faces an endogenous probability, $\Pi$, of not being reelected for period 2. If re-elected, the $R$-government sets its preferred policy, $f_{2}=f_{2}^{R}$ and $g_{2}=g_{2}^{R}$. If replaced, the policy of the succeeding $D$-government must be accepted, $f_{2}=f_{2}^{D}$ and $g_{2}=g_{2}^{D}$. Thus, the $R$-incumbent determines optimal policy in terms of $f_{1}, g_{1}$ and, consequently $b$, by the maximization of

$$
u_{1}^{R}\left(f_{1}, g_{1}\right)+\Pi u_{2}^{R}\left(f_{2}^{D}, g_{2}^{D}\right)+(1-\Pi) u_{2}^{R}\left(f_{2}^{R}, g_{2}^{R}\right),
$$

subject to (1), (2a) and (2b) and given perfect knowledge about i) how $\Pi$ depends on the chosen policy and ii) how the alternative $D$-government will behave in period 2 if elected. Our modeling of the voters' preferences will imply that $\Pi$ is a function of the intra-period split between $f_{1}$ and $g_{1}$ as well as the intertemporal distribution of resources $(b)$.

\footnotetext{
${ }^{8}$ If we choose the interpretation that $f_{t}$ and $g_{t}$ are respectively resources available for private and public spending, then we also have to assume that the unity-endowment applies to the whole economy.
} 
Analyzing how the incumbent will utilize the link between policy-choices and $\Pi$, we will compare the outcome with a benchmark case of certain reelection for the $R$-government, i.e., $\Pi=0$. It follows from (1), (2a), (2b) and (3), that our benchmark is given by

$$
f_{t}=\alpha^{R}, g_{t}=\left(1-\alpha^{R}\right) \text { and } b=0 \text {, for } t=1,2 \text {. }
$$

\subsection{Voters}

The utility of voter $i$ in group $j$ is given by

$$
u_{1}^{j}+u_{2}^{j}+\left(\sigma^{i j}+\delta\right) K^{D}
$$

where $u_{t}^{j}$ is the period $t$ utility of the provided package of public spending. The dummy variable $K^{D}$ is one in the case of party $D$ holding office in period 2 and zero in the case of party $R$. The parameter $\sigma^{i j}$ reflects an idiosyncratic bias towards party $D$ for voter $i$ belonging to group $j$. This bias reflects non-economic ideological factors, and has a mean-zero uniform distribution with density $\phi$ in both groups. The variable $\delta$ is a stochastic, aggregate popularity shock for party $D$. It is drawn from a meanzero uniform distribution with density $\psi$.

The period-utility functions of the voters in group $j$ are given by

$$
u_{t}^{j}=\alpha^{j} \log F_{t}+\left(1-\alpha^{j}\right) \log G_{t}(t=1,2),
$$

where $F_{t}$ and $G_{t}$ are the surplus spending levels on the two public goods, reflecting our specification of dynamic habit formation in the voters' preferences for public goods. Capturing that past spending levels increase the marginal utility of current spending levels (see Deaton 1992: 30 or Sundaresan 1989), we have that

(7a) $F_{t}=f_{t}-\gamma f_{t-1}$,

and

(7b) $G_{t}=g_{t}-\gamma g_{t-1}$,

where $\gamma, 0 \leq \gamma<1$, indicates the strength of the habit formation mechanism (and $\gamma=0$ implies additive separable preferences). The magnitudes of $f_{0}$ and $g_{0}$ are given by history. We assume that the relevant values of $\gamma$ ensure $F_{t}>0$ and $G_{t}>0$.

Capturing that group $j$ is the natural constituency of party $J$, we assume that $\alpha^{R}=\alpha^{r}$ and $\alpha^{D}=\alpha^{d}$. Still, the existence of ideological concerns and popularity shocks, as introduced in (5), and habit formation may all imply that segments of the voters may take voting decisions that are not in accordance with their fellow constituency members.

A crucial feature of the model is the fact that voters' preferences are characterized by habit formation, while this is not the case for the preferences of the parties. This reflects two concerns. First, we wish in particular to highlight that voters' preferences are endogenously determined by policies. This is modeled by a mechanism that is more transparent if the parties’ preferences do not change in 
response to the implemented policies. Second, studies of party manifestos suggest that political parties' policy preferences are relatively stable over time. Using post WWII time series data for 25 democracies, Budge and Klingemann (2001) report that - while there are some changes in party positions over time - estimated party preferences within individual countries do generally not leapfrog or overlap. Hence, it seems reasonable to assume that political parties to a large extent represent basic ideas, and implied views about resource allocation, that remain more stable over time than the preferences of large segments of the voters.

\section{The political equilibrium}

The timing of the political decisions is as follows: In period 1 the $R$-incumbent sets its preferred policy in terms of $f_{1}, g_{1}$ and $b$. There is no room for policy commitment. An election is held at the start of period 2. The winning party then sets period 2 policy in terms of $f_{2}$ and $g_{2}$. As usual, we solve the model backwards.

\subsection{Post election policy}

Assume that party $J$ wins the election. The chosen period 2 policy is then determined by the maximization of $u_{2}^{J}$, see (1), subject to (2b) when $b$ is inherited from period 1 . This yields

$$
f_{2}^{J}(b)=\alpha^{J}(1-b)
$$

and

(8b) $\quad g_{2}^{J}(b)=\left(1-\alpha^{J}\right)(1-b)$.

Utilizing the period 1 budget constraint, (2a), it follows from (7a), (7b), (8a) and (8b) that the realized period 2 surplus spending levels, $F_{2}=F_{2}^{J}$ and $G_{2}=G_{2}^{J}$, can be written as (reaction-) functions of $f_{1}$ and $g_{1}$ :

(9a) $\quad F_{2}^{J}\left(f_{1}, g_{1}\right)=\alpha^{J}\left(2-f_{1}-g_{1}\right)-\gamma f_{1}$,

(9b) $G_{2}^{J}\left(f_{1}, g_{1}\right)=\left(1-\alpha^{J}\right)\left(2-f_{1}-g_{1}\right)-\gamma g_{1}$.

An increase in the period 1 spending on one of the goods, say $f_{1}$, has two distinct effects on the period 2 surplus spending levels. The direct 'habit effect' lowers period's 2 surplus spending on the same good through a higher habit level, i.e., the effect of $f_{1}$ on the last term on the RHS of (9a). In addition, 
there is a 'debt effect' that lowers both surplus spending levels, i.e., the first term on the RHS of both (9a) and (9b). ${ }^{9}$

\subsection{Voting decisions}

Turning to voting decisions, we define $\bar{u}_{2}^{j}$ as the difference in period 2 utility for group $j$ if party $D$ rather than party $R$ wins the election. It follows from (6) that

$$
\bar{u}_{2}^{j}=\alpha^{j}\left(\log F_{2}^{D}-\log F_{2}^{R}\right)+\left(1-\alpha^{j}\right)\left(\log G_{2}^{D}-\log G_{2}^{R}\right) .
$$

Being perfectly informed about the intensions of the alternative governments, voter $i$ from group $j$ will choose to vote for party $D$ if $\sigma^{i j}>-\left(\bar{u}_{2}^{j}+\delta\right)$; see (5). Normalizing the size of each of the two groups to $\frac{1}{2}$, it follows (as seen by the illustration in Figure 1) that the number of voters for party $D$ is

$$
N^{D}=\frac{1}{2}\left(\frac{1}{2}+\left(\bar{u}_{2}^{d}+\delta\right) \phi\right)+\frac{1}{2}\left(\frac{1}{2}+\left(\bar{u}_{2}^{r}+\delta\right) \phi\right)=\frac{1}{2}+\frac{1}{2}\left(\bar{u}_{2}^{d}+\bar{u}_{2}^{r}\right) \phi+\delta \phi .
$$

\section{*** Fig. 1}

*** Fig. 2

We have that $\Pi\left(f_{1}, g_{1}\right)=\operatorname{Prob}\left(N^{D}>\frac{1}{2}\right)$. Recalling that the popularity shock, $\delta$, is uniformly distributed with a zero mean and a density equal to $\psi$, it follows from (11) that

$$
\Pi\left(f_{1}, g_{1}\right)=\frac{1}{2}+\psi \frac{1}{2}\left(\bar{u}_{2}^{d}+\bar{u}_{2}^{r}\right),
$$

see Figure 2. Consequently, in order to investigate how the period 1 policy influences the probability of reelection, we have to consider the derivatives:

$$
\begin{aligned}
& \frac{d \Pi}{d f_{1}}=\frac{1}{2} \psi\left(\frac{d \bar{u}_{2}^{d}}{d f_{1}}+\frac{d \bar{u}_{2}^{r}}{d f_{1}}\right), \\
& \frac{d \Pi}{d g_{1}}=\frac{1}{2} \psi\left(\frac{d \bar{u}_{2}^{d}}{d g_{1}}+\frac{d \bar{u}_{2}^{r}}{d g_{1}}\right) .
\end{aligned}
$$

From (9a), (9b), (10) and the assumption that $\alpha^{R}=1-\alpha^{D}$, we derive

$$
\frac{d \bar{u}_{2}^{d}}{d f_{1}}+\frac{d \bar{u}_{2}^{r}}{d f_{1}}=\gamma\left(\frac{1}{F_{2}^{R}}-\frac{1}{F_{2}^{D}}\right)-\alpha^{D}\left(\frac{1}{F_{2}^{D}}-\frac{1}{G_{2}^{R}}\right)-\left(1-\alpha^{D}\right)\left(\frac{1}{G_{2}^{D}}-\frac{1}{F_{2}^{R}}\right),
$$

\footnotetext{
${ }^{9}$ By (9a) and (9b), period 1 policies must fulfill $\gamma<\alpha^{D}(1-b) / f_{1}$ and $\gamma<\left(1-\alpha^{R}\right)(1-b) / g_{1}=\alpha^{D}(1-b) / g_{1}$, respectively, for utility in period 2 to be well-defined (see equations $3 a$ and $3 b$ ). We assume that these restrictions hold.
} 
where the first term on the RHS captures the habit effect as defined above and the two remaining terms capture the debt effect. Using (9a) and (9b), we collect the last two terms and rewrite (14a):

$$
\frac{d \bar{u}_{2}^{d}}{d f_{1}}+\frac{d \bar{u}_{2}^{r}}{d f_{1}}=\gamma\left(\frac{1}{F_{2}^{R}}-\frac{1}{F_{2}^{D}}\right)+\gamma\left(f_{1}-g_{1}\right)\left[\frac{1-\alpha^{D}}{F_{2}^{R} G_{2}^{D}}-\frac{\alpha^{D}}{F_{2}^{D} G_{2}^{R}}\right]
$$

Because $\alpha^{R}>\alpha^{D}$ and, accordingly, $F_{2}^{R}>F_{2}^{D}$, the habit effect is negative. This means that more settled habits reduce voters' utility of given levels of $f_{2}^{J}$. Because $f_{2}^{D}<f_{2}^{R}$, the concavity of the utility function implies that the drop in all voters' utility is larger in the case of a $D$-government than for an $R$-government.

Noting that the term in brackets in the last part of the RHS of (14b) is negative (as shown in the Appendix), we conclude that the debt effect has the opposite sign of $\left(f_{1}-g_{1}\right)$. This reflects that a higher debt reduces both $f_{2}^{J}$ and $g_{2}^{J}$, which lower voters' surplus spending levels disproportionally, depending on the magnitudes of the habit levels, $\gamma f_{1}$ versus $\gamma g_{1}$. If $f_{1}>g_{1}$, the drop in $F_{2}^{J}$ is more painful than the drop in $G_{2}^{J}$, implying that all voters' assessment of the political parties are tilted in the favor of the $R$-government that will ensure the smallest reduction in $f_{2}$. Correspondingly, the case of $f_{1}<g_{1}$ implies a debt effect that favors voters' assessment of the $D$-party. Summing up, it follows for $\gamma>0$ that the expression in (14b) is strictly negative if $f_{1} \geq g_{1}$ and ambiguous if $f_{1}<g_{1}$.

The derivation of how $\bar{u}_{2}^{d}+\bar{u}_{2}^{r}$ responds to changes in $g_{1}$ is analogous. Using (9a), (9b) and (10), we compute

$$
\frac{d \bar{u}_{2}^{d}}{d g_{1}}+\frac{d \bar{u}_{2}^{r}}{d g_{1}}=\gamma\left(\frac{1}{G_{2}^{R}}-\frac{1}{G_{2}^{D}}\right)+\gamma\left(f_{1}-g_{1}\right)\left[\frac{1-\alpha^{D}}{F_{2}^{R} G_{2}^{D}}-\frac{\alpha^{D}}{F_{2}^{D} G_{2}^{R}}\right] .
$$

The habit effect of a higher $g_{1}$ favors party $D$, i.e., the first term on the RHS is positive, while the debt effect also favors party $D$ if $g_{1}>f_{1}$. Provided that $\gamma>0$, the expression in (15) is therefore strictly positive if $g_{1} \geq f_{1}$ and ambiguous if $g_{1}<f_{1}$.

Returning to the effects on the probability of reelection of changes in respectively $f_{1}$ and $g_{1}$ (including the induced debt effect), we observe from (13a) and (13b) that they are proportional to the derivatives in (14b) and (15). The effects are also proportional to the magnitude of the density $\psi$. As illustrated in Figure 2, this simply reflects that a higher $\psi$ implies that a given change in $\bar{u}_{2}^{d}+\bar{u}_{2}^{r}$ will influence the voting behavior of a larger group of voters. Moreover, it follows from (14b) and (15) that the ability of the incumbent to use current policies to influence $\Pi$ hinges on the habit formation mechanism, i.e., $\gamma>0 .^{10}$

\footnotetext{
${ }^{10}$ Note that in the probabilistic voting framework of Persson and Tabellini (2000: section 13.3) the ability of the incumbent to influence the probability of reelection hinges completely on the assumption that the uniform distributions for $\sigma^{i R}$ and
} 


\subsection{Equilibrium policy}

The $R$-incumbent sets policy in period 1 . This policy is his best response to the derived expected reaction of the voters (at the election) and to the derived policy of the opposition if they seize power in period 2.

Using (1), (8a), (8b), (2a) and the condition $\alpha^{D}=1-\alpha^{R}$, we rewrite the expected utility function of the $R$-incumbent, (3), as

$$
\alpha^{R} \log f_{1}+\left(1-\alpha^{R}\right) \log g_{1}+\log \left(2-f_{1}-g_{1}\right)+A+B \Pi\left(f_{1}, g_{1}\right)
$$

Here $A$ and $B$ are negative constants (recall that $\alpha^{R}>\alpha^{D}$ ),

$$
\begin{aligned}
& A=\alpha^{R} \log \alpha^{R}+\left(1-\alpha^{R}\right) \log \left(1-\alpha^{R}\right)<0, \\
& B=\left(1-2 \alpha^{R}\right)\left(\log \alpha^{R}-\log \left(1-\alpha^{R}\right)\right)<0 .
\end{aligned}
$$

Maximization of (3b) with respect to $f_{1}$ and $g_{1}$ yields the first-order conditions

(18a) $\frac{\alpha^{R}}{f_{1}}-\frac{1}{2-f_{1}-g_{1}}+B \frac{d \Pi}{d f_{1}}=0$,

(18b) $\frac{1-\alpha^{R}}{g_{1}}-\frac{1}{2-f_{1}-g_{1}}+B \frac{d \Pi}{d g_{1}}=0$.

It is useful first to consider the corner case of no habit formation mechanism, i.e., $\gamma=0$, which implies that $\frac{d \Pi}{d f_{1}}=0$ and $\frac{d \Pi}{d g_{1}}=0$. We then obtain $f_{1}=\alpha^{R}, g_{1}=\left(1-\alpha^{R}\right)$ and, from (2a), $b=0$. This is equivalent to the benchmark case of a certain reelection, see (4). The intuition follows from TA (1990). When $\Pi$ is exogenous and less than one, the incumbent on the one hand benefits from increased debt because it provides more of the most preferred composition of public spending today and, as a consequence of less total future spending, it also "forces" the potential alternative government to set the composition of public spending in period 2 closer to the incumbent's preferences. One the other hand, increased debt harms the incumbent because it implies a less smooth utility profile over time. The degree of concavity in the utility function determines whether a debt or surplus bias is optimal on strategic grounds. ${ }^{11}$ It turns out that log utility is the borderline case where the two opposite effects exactly cancel out. In the context of the present paper that assumes log utility at the outset, this is a useful property because it allows us to focus exclusively on the strategic effects of current policies on $\Pi$.

From (18a) and (18b), we obtain

\footnotetext{
$\sigma^{i D}$ have different densities. By the assumption of a similar density $\psi$, this mechanism is deliberately disregarded in our model.

${ }^{11}$ In the extreme case of completely opposite preferences, $\alpha^{R}=\left(1-\alpha^{D}\right)=1$, a debt bias is always optimal when $\Pi<1$ because the incumbent will regard the alternative government's spending as pure waste.
} 


$$
\frac{\alpha^{R}}{f_{1}}-\frac{1-\alpha^{R}}{g_{1}}=B\left(\frac{d \Pi}{d g_{1}}-\frac{d \Pi}{d f_{1}}\right) .
$$

Using (13a), (13b), (14b) and (15), it is straightforward to verify that

$$
\left(\frac{d \Pi}{d g_{1}}-\frac{d \Pi}{d f_{1}}\right)=\frac{1}{2} \psi \gamma\left[\left(\frac{1}{G_{2}^{R}}-\frac{1}{G_{2}^{D}}\right)-\left(\frac{1}{F_{2}^{R}}-\frac{1}{F_{2}^{D}}\right)\right]>0 \text { for } \gamma>0 .
$$

Recalling that the constant $B$ is strictly negative, see (17), we conclude from (19) that:

PROPOSITION 1: When $\gamma>0$, the period 1 R-incumbent sets $f_{1}$ and $g_{1}$ such that $\frac{f_{1}}{g_{1}}>\frac{\alpha^{R}}{1-\alpha^{R}}$.

Comparing to the benchmark case of a certain reelection (see (4)), or the case with an exogenous reelection probability $(\gamma=0)$, this proposition implies that the incumbent chooses a more polarized allocation between the two public goods in the sense that the size of the gap $f_{1}-g_{1}>0$ has increased. Thus, rather than to cater to the middle as predicted by a median voter model, the incumbent's political-strategic reasoning leads him to choose a more extreme intra-period distribution of the two public goods.

In order to consider debt policy, we note that the first-order conditions (18a) and (18b) imply

$$
f_{1}+g_{1}=1+\frac{1}{2}\left(2-f_{1}-g_{1}\right) B\left[f_{1} \frac{d \Pi}{d f_{1}}+g_{1} \frac{d \Pi}{d g_{1}}\right] \text {. }
$$

Because $B<0$ and $\left(2-f_{1}-g_{1}\right)>0$, it follows that $f_{1}+g_{1}>1$ if the term in brackets on the RHS is strictly negative. As demonstrated in the Appendix, this condition is satisfied when $\gamma>0$. Thus:

PROPOSITION 2: Given $\gamma>0, b>0$.

Moreover, from Proposition 1 and Proposition 2, we immediately obtain:

PROPOSITION 3: Given $\gamma>0$, the R-incumbent sets $f_{1}>\alpha^{R}$.

Consequently, the incumbent's choice of polarization in the sense of a larger gap between $f_{1}$ and $g_{1}$ involves an increase in the supply of his most preferred good - as compared to the case of certain reelection.

Propositions 1 and 2 imply that the incumbent chooses to "pay" for the greater probability of reelection by deviating from both his intra- and intertemporal first-best allocation of resources. We note that he could have increased the reelection probability by deviating only along the intra-period 
dimension. Indeed, it is straightforward to show that proposition 1 holds even in the absence of debt. ${ }^{12}$ Allowing for debt, it turns out that the cost to the incumbent of a given decrease in $\Pi$ is minimized when the distortion incurred due to polarization is smoothed by an intertemporal distortion caused by $b>0$. Thus, debt allows the $R$-incumbent to widen the gap between $f_{1}$ and $g_{1}$ by means of a jump in $f_{1}$ (i.e., proposition 3) which is not fully compensated by a similar drop in $g_{1}$.

Our analysis can be summarized by Figure $3 .^{13}$ In this figure, the intra-period indifference curves of the $R$-incumbent are denoted I, II, III and IV. The period 2 expansion path of the potential $D$ successor is given by $\mathrm{EP}^{\mathrm{D}}$, while the expansion path of the $R$-government in the case of $\gamma=0$ (i. e. when $\Pi$ is exogenous) is given by $\left.\mathrm{EP}^{\mathrm{R}}\right|_{\gamma=0}$. The benchmark solution of a certain reelection for the $R$-incumbent is given by point $\mathrm{B}^{\mathrm{R}}$ on the $b=0$ budget line (in both periods). As explained above, the $R$-incumbent would also choose point $\mathrm{B}^{\mathrm{R}}$ in period 1 when $\Pi$ is exogenous and satisfies $0<\Pi<1$. Then the period 2 allocations would be either at point $\mathrm{B}^{\mathrm{R}}$ if $\mathrm{R}$ wins the election or at point $\mathrm{B}^{\mathrm{D}}$ if $D$ wins.

Given that the $R$-incumbent can influence $\Pi$, the optimal period 1 allocation is given by $R_{1}$. Comparing to $\mathrm{B}^{\mathrm{R}}$, the $R$-incumbent chooses $b>0$, a larger gap between $f_{1}$ and $g_{1}$ and finally $f_{1}>\alpha^{R}$. The $R$-incumbent now incurs costs in terms of both an inefficient intra-period allocation of resources in period 1 and an inefficient intertemporal allocation. These costs are worthwhile, however, because they are dominated by the increase in expected period 2 utility caused by a higher probability for the $\mathrm{R}_{2}$ allocation in period 2 rather than the $\mathrm{D}_{2}$ allocation. ${ }^{14}$

\section{*** Fig. $3 * * *$}

\section{Final remarks}

This paper has put forward a probabilistic voting model where habit formation in the voters' preferences for alternative public goods implies a link from current policies, in terms of decisions on the composition of public goods and debt, to the probability for reelection. A forward-looking and output oriented politician who faces the chance of being replaced by an alternative government with different preferences for the composition of public goods, will act strategically and utilize this link in order to increase the probability of reelection. Comparing to either the benchmark case of a certain

\footnotetext{
${ }^{12}$ If $b$ is set exogenously equal to zero, most of the analysis is simplified somewhat. Terms in equations (8a), (8b), (9a), (9b), (14a), (14b) and (15) become zero. The key equations (19) and (20) are not altered, however, leaving proposition 1 unchanged.

${ }^{13}$ Figure 3 is inspired by Figure 1 in TA (1990: 44).

${ }^{14}$ Corner solutions are avoided as long as $0<\alpha^{J}<1$, because marginal utilities will approach infinity when public good supplies approach zero.
} 
reelection or the case of an exogenous probability of reelection (due to $\gamma=0$ ), we have shown that the incumbent chooses a larger initial period budget share for his most preferred public good. This pushes up all voters' habit levels for this good. As a consequence, all voters' assessments of the incumbent's preferred future policy will be more favorable, leading in turn to a higher probability of reelection. Moreover, we have also demonstrated that the greater polarization in the resource allocation in the initial period is accompanied by a deficit bias.

Our predictions call for a search for empirical evidence. As mentioned in the introduction, Glaeser et al. (2005) and McCarty et al. (2006) report some striking observations of seemingly surprisingly polarized policies in the United States along several dimensions. We also argued that the US public spending and deficit patterns observed during the Reagan era were consistent with the predictions of our analysis. It is still fair to say that formalized empirical evidence of polarized policies is in short supply. Looking at the debt-dimension, there are plenty of observations of sustained public deficits in many major OECD economies (see for example OECD 2006). As surveyed by Persson and Tabellini (2000: section 13.3.4) it has proven hard to provide robust empirical evidence for suggested strategic motives. ${ }^{15}$

With respect to AT (1990) and TA (1990), their prediction of an inverse relationship between the magnitude of the (exogenous) probability of reelection and the size of the deficit has been rejected by existing empirical studies. Our findings suggest a quite different relationship, however: a deficit and a polarized resource allocation are means used by the incumbent to increase the probability of reelection. Thus, we believe that careful empirical analyses of potential co-movements between these three variables are warranted. As a motivation for such an effort in the future, we note that our finding seems to be in the spirit of the theory of political business cycles and loosely consistent with the stylized fact (as presented by Persson and Tabellini 2000: 393) that budget deficits tend to be larger during election years.

Another interesting avenue for future research is to introduce a richer modeling of possible variations in the key parameters of politicians' and voters' utility functions. For example, the model could possibly be extended by allowing parties to choose their ideologies by electing their leaders. ${ }^{16}$ Presumably, the parties would elect leaders with an ideology (as represented by $\alpha^{J}$ ) that matches the established voter-habits. Our conjecture is that this would reinforce the extremism highlighted in this paper. The cost of choosing an extreme policy for a strategically elected leader would conceivably be lower than for an 'ordinary' party member. The exact mechanisms of a model where parties choose their ideologies are, however, left for future research. Another potentially promising extension is to let the strength of an individual voter's habit formation for a particular public good be determined by his

\footnotetext{
${ }^{15}$ One exception is a study by Petterson (2001). Using data for Swedish municipalities, he finds strong support for the strategic budget motive suggested by Persson and Svensson (1989). Crain and Tollison (1993) and Besley and Case (1995) provide related evidence on the impact of political incentives on fiscal policy in US states.

${ }^{16}$ This idea borrows from the monetary policy literature that demonstrates that it might be optimal for a government to appoint a conservative central bank governor; see Rogoff (1985).
} 
or her direct or indirect exposure to the good in question, i.e., voters that, for example, have been hospitalized may develop stronger habits for health services than other voters.

\section{Appendix}

\section{Last term on the RHS of (14b)}

In order to determine the sign of the term in brackets on the RHS of (14b), we note that:

(A-1) $\left[\frac{1-\alpha^{D}}{F_{2}^{R} G_{2}^{D}}-\frac{\alpha^{D}}{F_{2}^{D} G_{2}^{R}}\right]=\frac{\left(1-\alpha^{D}\right) F_{2}^{D} G_{2}^{R}-\alpha^{D} F_{2}^{R} G_{2}^{D}}{F_{2}^{D} G_{2}^{R} F_{2}^{R} G_{2}^{D}}$.

Substituting from (9a) and (9b) and using that $\alpha^{R}=1-\alpha^{D}$, we rewrite the numerator as

$$
\begin{array}{r}
\left(\alpha^{D}\left(1-\alpha^{D}\right)\left(2-f_{1}-g_{1}\right)-\left(1-\alpha^{D}\right) \gamma f_{1}\right)\left(\alpha^{D}\left(2-f_{1}-g_{1}\right)-\gamma g_{1}\right) \\
-\left(\alpha^{D}\left(1-\alpha^{D}\right)\left(2-f_{1}-g_{1}\right)-\alpha^{D} \gamma f_{1}\right)\left(\left(1-\alpha^{D}\right)\left(2-f_{1}-g_{1}\right)-\gamma g_{1}\right)
\end{array} .
$$

Because $\alpha^{D}<\frac{1}{2}$ and $2-f_{1}-g_{1}>0$, the numerator must be strictly negative, implying that the terms in brackets on the RHS of (14b) must be strictly negative as well.

\section{Proof of Proposition 2}

Proposition 2 hinges on the condition that the term in brackets on RHS of (21) is strictly negative,

(A-2) $\left[f_{1} \frac{d \Pi}{d f_{1}}+g_{1} \frac{d \Pi}{d g_{1}}\right]<0$.

Substituting from (13a), (13b), (14a) and (14b), and collecting terms, this condition can be written as

$$
\frac{1}{2} \psi\left[\gamma\left(f_{1}-g_{1}\right)\left(\frac{1-\alpha^{D}}{G_{2}^{D} F_{2}^{R}}-\frac{\alpha^{D}}{F_{2}^{D} G_{2}^{R}}\right)\left(f_{1}+g_{1}\right)+\gamma f_{1}\left(\frac{1}{F_{2}^{R}}-\frac{1}{F_{2}^{D}}\right)+\gamma g_{1}\left(\frac{1}{G_{2}^{R}}-\frac{1}{G_{2}^{D}}\right)\right]<0
$$

By Proposition 1 we have that $f_{1}>g_{1}$. Using that the first part of this Appendix proves that the expression in (A-1) is strictly negative, it follows that a sufficient condition for (A-2) to hold is

$$
f_{1}\left(\frac{1}{F_{2}^{R}}-\frac{1}{F_{2}^{D}}\right)+g_{1}\left(\frac{1}{G_{2}^{R}}-\frac{1}{G_{2}^{D}}\right) \leq 0 .
$$

Taking into account that $f_{1}>g_{1}, F_{2}^{R}>F_{2}^{D}$ and $G_{2}^{D}>G_{2}^{R}$, (A-4) holds if

$$
\left|\frac{1}{F_{2}^{R}}-\frac{1}{F_{2}^{D}}\right| \geq\left|\frac{1}{G_{2}^{R}}-\frac{1}{G_{2}^{D}}\right|
$$

which after straightforward manipulations can be written as

(A-6) $\frac{\alpha^{R}(1-b)-\gamma f_{1}}{\alpha^{R}(1-b)-\gamma g_{1}} \leq \frac{\left(1-\alpha^{R}\right)(1-b)-\gamma g_{1}}{\left(1-\alpha^{R}\right)(1-b)-\gamma f_{1}}$. 
This condition is obviously satisfied because $f_{1}>g_{1}$. This implies that condition (A-2) and in turn Proposition 2 are satisfied as well. 


\section{References}

Aghion, P. \& P. Bolton (1990). Government domestic debt and the risk of default: A politicaleconomic model of a strategic role of debt. In R. Dornbusch and M. Draghi (Eds.), Public Debt Management. Theory and History (pp. 315-345). Cambridge: Cambridge University Press.

Alesina, A. (1988). Credibility and policy convergence in a two-party system with rational voters. American Economic Review, 78, 796-805.

Alesina, A. \& G. Tabellini (1990). A positive theory of fiscal deficits and government debt. Review of Economic Studies, 57, 403-414.

Alesina, A. \& N. Fuchs-Schündeln (2007). Good bye Lenin (or not?): The effect of communism on people's preferences. American Economic Review, 97, 1507-1528.

Alesina, A. \& R.T. Holden (2008). Ambiguity and extremism in elections. NBER working paper no. 14143, National Bureau of Economic Research, Cambridge.

Besley, T. and A. Case (1995). Does Electoral Accountability Affect Economic Policy Choices? Evidence from Gubernatorial Term Limits. Quarterly Journal of Economics, 110, 769-798. (Reprinted in C.K. Rowley, W. F. Shughart II and RD. Tollison (Eds.), The Economics of Budget Deficits. Northampton (Mass.): Edward Elgar Publishing, 2002.)

Budge, I. \& H-D. Klingemann (2001). Finally! Comparative over-time mapping of part policy movement. In I. Budge et al. (Eds.), Mapping policy preferences: Estimates for parties, electors, and governments 1945-1988 (pp. 19-50). Oxford: Oxford University Press.

Campbell, J.Y. \& J.H. Cochrane (1999). By force of habit: A consumption-based explanation of aggregate stock market behavior. Journal of Political Economy, 107, 205-251.

Caporale, M.C., Y. Georgellis, N. Tsitsianis \& Y.P. Yin (2007). Income and happiness across Europe: Do reference values matter? CESifo working paper no. 2146, University of Munich, Munich.

Carroll, C.D., J. Overland \& D.N. Weil (2000). Saving and growth with habit formation. American Economic Review, 90, 341-355.

Cassing, J.H. \& A.L. Hillman (1986). Shifting comparative advantage and senescent industry collapse. American Economic Review, 76, 516-523.

Crain, W.M. (2001). Institutions, durability, and the value of political transactions. In W.F. Shughart II and L. Razzolini (Eds.), The Elgar companion to public choice (pp. 183-196). Northampton (Mass.): Edward Elgar Publishing.

Crain, W.M. and R.T. Tollison (1993). Time inconsistency and fiscal policy: Empirical analysis of U.S. States, 1969-89. Journal of Public Economics, 51, 153-159. (Reprinted in C.K. Rowley, W. F. Shughart II and RD. Tollison (Eds.), The Economics of Budget Deficits. Northampton (Mass.): Edward Elgar Publishing, 2002.)

Cukierman, A. \& M. Tommasi (1998). When does it take a Nixon to go to China? American Economic Review, 88, 180-197.

Cukierman, A., S. Edwards \& G. Tabellini (1992). Seignorage and political instability. American Economic Review, 82, 537-555. 
Deaton, A. (1992). Understanding consumption. Oxford: Oxford University Press.

Duesenberry, J.S. (1949). Income, saving and the theory of consumer behavior. Cambridge (Mass.): Harvard University Press.

Easterlin, R.A. (1974). Does economic growth improve the human lot? Some empirical evidence. In P.A. David and M.W. Reider (Eds.), Nations and households in economic growth: Essays in honor of Moses Abramovitz (pp. 89-125). New York: Academic Free Press.

Fredrick, S. \& G. Loewenstein (1999). Hedonic adaptation. In D. Kahneman, E. Diener and N. Schwarz (Eds.), Well-Being: The foundations of hedonic psychology (pp. 302-329). New York: Russell Sage Foundation.

Glaeser, E.L., G.A.M. Ponzetto \& J.M. Shapiro (2005). Strategic extremism: Why democrats and republicans divide on religious values. Quarterly Journal of Economics, 120, 1283-1330.

Glazer, A. (1989). Politics and the choice of durability. American Economic Review, 79, 1207-1214.

Glazer, A., M. Gradstein \& K.A. Konrad (1998). The electoral politics of extreme policies. Economic Journal, 108, 1677-1685.

Kahneman, D. \& A. Tversky (1979). Prospect Theory: An Analysis of Decision under Risk. Econometrica, 47, 263-91.

Ljungqvist, L. \& H. Uhlig (2000). Tax policy and aggregate demand management under catching up with the Joneses. American Economic Review, 90, 356-366.

McCarty, N., K. Poole \& H. Rosenthal (2006). Polarized America. Cambridge (Mass.): MIT Press.

OECD (2006). Economic Outlook 80, Paris.

Persson, T. \& L.E.O. Svensson (1989). Why a stubborn conservative would run a deficit: Policy with time-inconsistent preferences. Quarterly Journal of Economics, 104, 325-345.

Persson, T. \& G. Tabellini (2000). Political economics: Explaining economic policy. Cambridge (Mass.): MIT Press.

Petterson, P. (2001). An empirical investigation of the strategic use of debt. Journal of Political Economy, 109, 570-584.

Powell, C.L. (1995). A soldier’s way - An autobiography. London: Random House Publishers.

Rabin, M. (1998). Psychology and economics. Journal of Economic Literature, 36, 11-46.

Rabin, M. (2002). A perspective on psychology and economics. European Economic Review, 46, 657685.

Rabinowitz, G. \& S.E. Macdonald (1989). A directional theory of issue voting. American Political Science Review, 83, 91-121.

Rogoff, K. (1985). The optimal degree of commitment to an intermediate monetary target. Quarterly Journal of Economics, 100, 1169-1189 
Romer, P.M. (1996). Preferences, promises, and the politics of entitlement. In V.R. Fuchs (Ed.), Individual and social responsibility: Child care, education, medical care and long-term care in America (pp. 195-220). Chicago: The University of Chicago Press.

Ryder, H.E. Jr. \& G.M. Heal (1973). Optimal growth with intertemporally dependent preferences. Review of Economic Studies, 40, 1-33.

Solnick, S.J. \& D. Hemenway (2005). Are positional concerns stronger in some domains than in others? American Economic Review, 95, 147-151.

Sundaresean, S.M. (1989). Intertemporally dependent preferences and the volatility of consumption and wealth. Review of Financial Studies, 2, 73-89.

Tabellini, G. \& A. Alesina (1990). Voting on the budget deficit. American Economic Review, 80, 3749. 
Fig. 1 Vote share of party D in group $j, j=d, r$

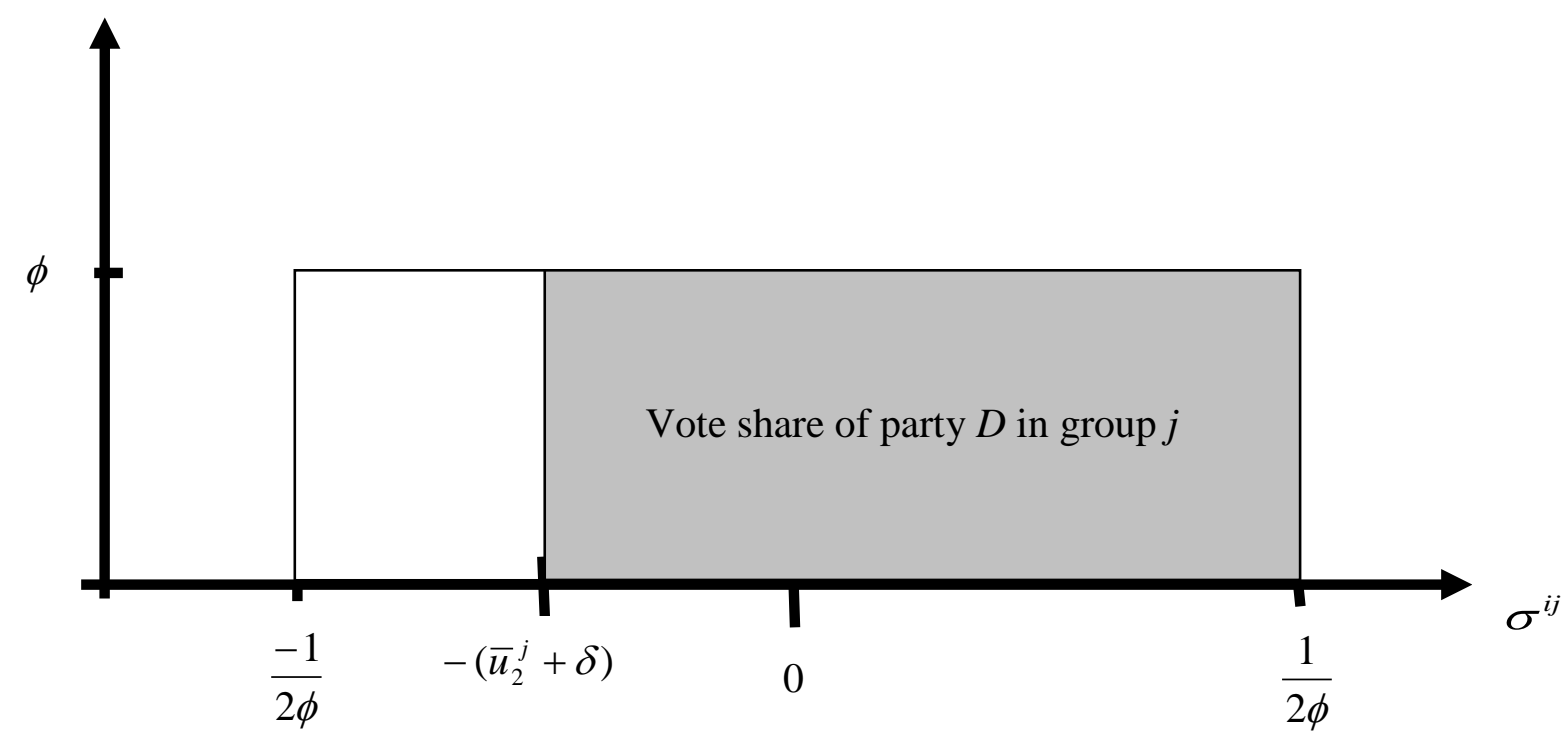

Fig. 2 The probability that party $D$ wins the election

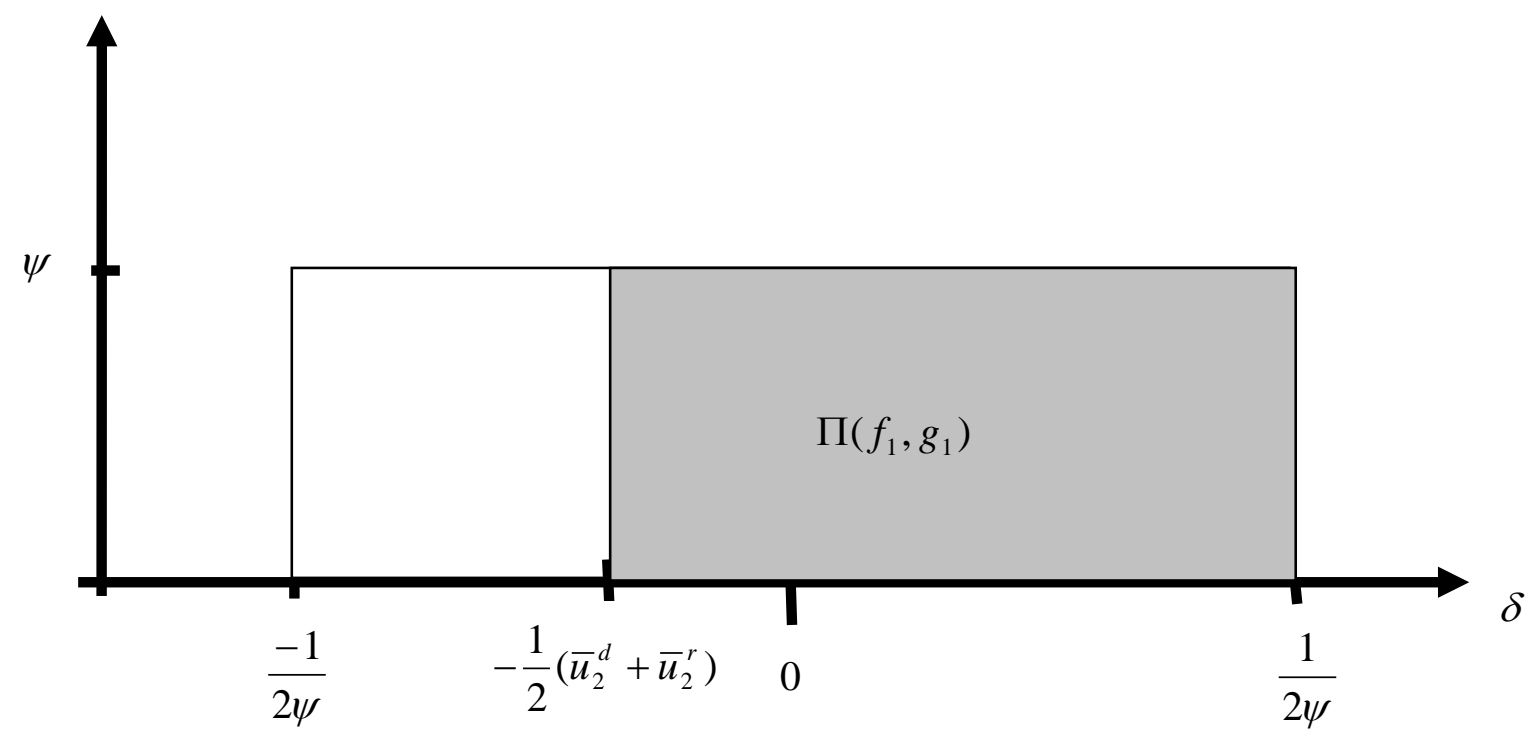


Fig. 3 Optimal policies

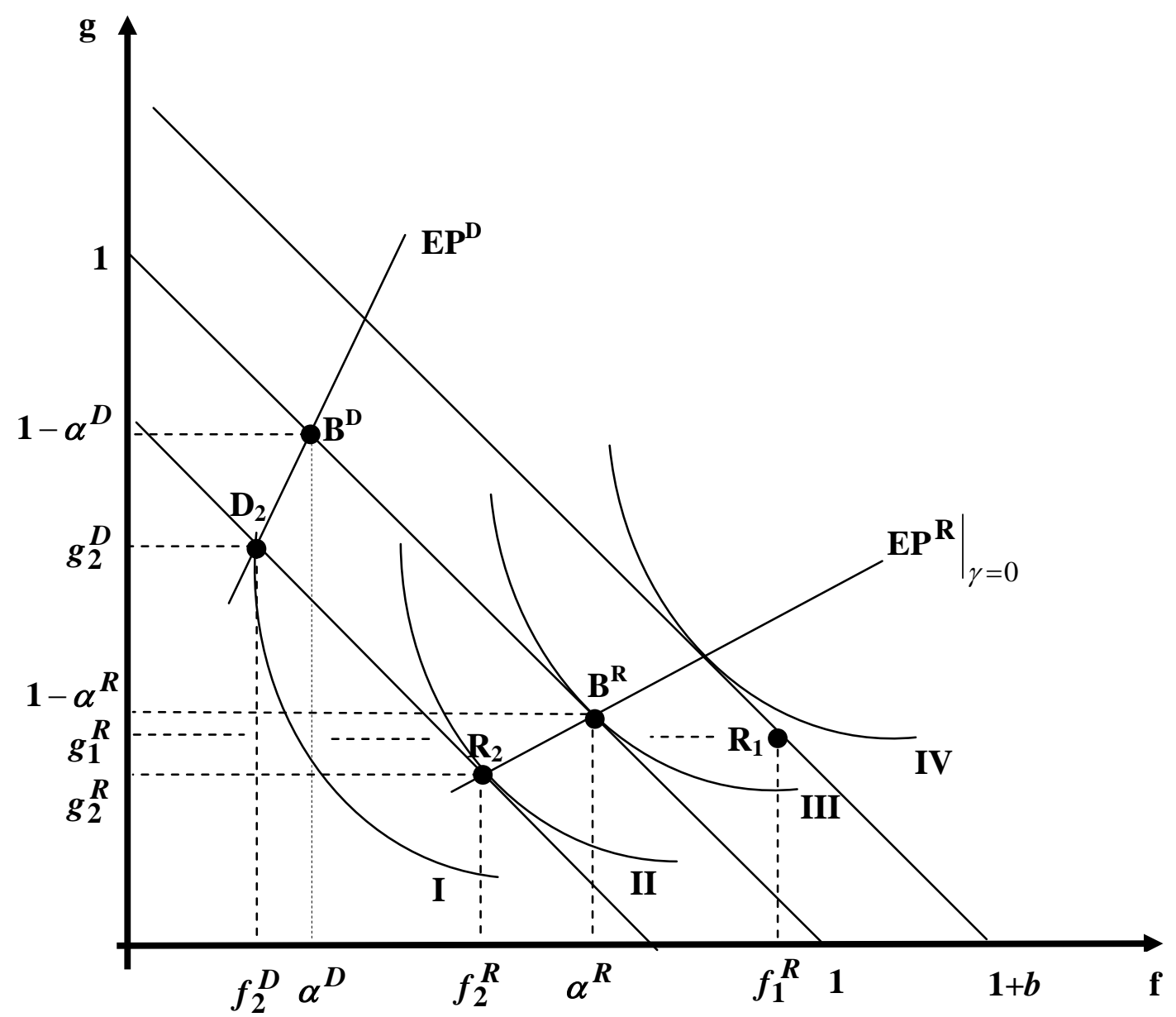

